\title{
ESTADO E SOCIEDADE CIVIL NA TEORIA POLÍTICA FRANCESA DO SÉCULO XIX: 0 DEBATE SOBRE A FORMAÇÃO DA SOCIEDADE PÓS-REVOLUCIONÁRIA ${ }^{1}$
}

\author{
Paulo Henrique Paschoeto Cassimiro ${ }^{\mathrm{a}}$
}

aFaz pós-doutorado no Departamento de Ciência Política da

Universidade de São Paulo, SP, Brasil.

E-mail:phpcassimiro@gmail.com.

Orcid: 0000-0003-2986-6580

Felipe Freller ${ }^{b}$

${ }^{b}$ Doutorando em Ciência Política pela Universisade de

São Paulo, SP, Brasil, e pela École des Hautes Études en Sciences Sociales (EHESS), França. E-mail: felipe@freller.net.

Orcid: 0000-0002-2402-5742

http://dx.doi.org/10.1590/0102-109141/111

\section{Introdução}

Se a interpretação de que a Revolução Francesa consagrou uma nova forma de sociedade se tornou praticamente consensual na teoria política, não se pode dizer que há consenso a respeito dos fundamentos dessa nova ordem social, que são, desde o final do século XVIII, objeto de intensa polêmica. A separação entre a sociedade civil - esfera de

\footnotetext{
${ }^{1} \mathrm{O}$ autor Paulo Henrique agradece à Fundação de Amparo à Pesquisa do Estado de São Paulo (FAPESP) que financiou, através de seu programa de Pós-Doutorado (processo $\mathrm{n}^{\text {o }}$ 2019/09549-1), a execução parcial da pesquisa apresentada neste artigo. $\mathrm{O}$ autor Felipe Freller agradece à Fundação de Amparo à Pesquisa do Estado de São Paulo (FAPESP), que financiou, por meio dos processos 2010/08019-4, 2012/20299-8, 2013/10776-6, 2015/21607-6 e 2017/03986-5, a execução parcial da pesquisa apresentada neste artigo.
} 
domínio do indivíduo-cidadão, sujeito da legitimidade política - e o Estado - entendido como esfera do exercício do poder legítimo resultado dos mecanismos de representatividade - constitui a forma política dessa nova sociedade; o debate em torno das diversas concepções de representação, dos direitos, das liberdades públicas e das funções dos poderes percorre os séculos XIX e XX, buscando construir a nova legitimidade política para o mundo que emerge da era das revoluções. Duas características centrais marcam a natureza da reflexão sobre a legitimidade política na nova sociedade pós-revolucionária (ou sociedade moderna, se preferirmos): por um lado, não se pode mais reivindicar fundamentos teológicos ou transcendentais para sustentar a legitimidade da ordem política; por outro lado, torna-se central encontrar os fundamentos históricos da sociedade moderna, relacionados ao problema de sua formação de longa duração.

A questão dos fundamentos históricos da sociedade 110 moderna se torna particularmente sensível nos debates políticos e historiográficos da França do século XIX, na qual, nas palavras de Stanley Mellon (1958), “a História se torna a linguagem da política" (p. 1). Pode-se argumentar que a História secular da Europa assume, no século XIX, um papel análogo ao da história bíblica em séculos anteriores. Com efeito, é a interpretação da História secular da Europa que passa, após a Revolução Francesa, a fornecer a chave de interpretação da nova ordem social e política europeia incluindo aí o problema de sua legitimidade e dos cursos legítimos de ação política em seu interior. Não é de se surpreender que a interpretação da História secular da Europa tenha se tornado, a partir de então, tão controversa e tão embrenhada de consequências práticas quanto havia sido, até então, a interpretação das Sagradas Escrituras.

No contexto particular da França, pode-se afirmar que o debate sobre a formação histórica da sociedade moderna tem se concentrado, desde a Revolução Francesa até os 
dias de hoje, na questão dos papéis respectivos do Estado e da sociedade civil na produção dessa nova ordem social e política; é possível dizer que essa questão aparece com força desde a eclosão da Revolução Francesa e continua a ser discutida atualmente. ${ }^{2}$ Tome-se como ilustração o livro Le modèle politique français: la société civile contre le jacobinisme de 1789 à nos jours ( $\mathrm{O}$ modelo político francês: A sociedade civil contra o jacobinismo de 1789 até nossos dias, em tradução livre), publicado por Pierre Rosanvallon em 2004. Nele, o autor promove uma crítica ao que chama de uma "vulgata tocquevilliana”, a qual teria constituído uma representação influente da formação histórica da sociedade francesa como congelada por "um Estado onipotente regendo sem obstáculos uma sociedade civil atomizada, desorganizada e subjugada"3 (Rosanvallon, 2004, p. 10). Em contraposição a essa difundida vulgata, Rosanvallon se propõe a escrever uma história moderna da França capaz de interligar as tendências do Estado francês à centralização e à dominação da sociedade civil (tendências essas que passaram a ser compreendidas pela referência vaga ao "jacobinismo") com as resistências e obstáculos que a sociedade civil nunca teria deixado de apresentar a esse "jacobinismo" (Rosanvallon, 2004, pp. 11-12). O próprio projeto de Rosanvallon demonstra o quanto a discussão sobre os papéis respectivos do Estado e da sociedade civil na formação da moderna sociedade francesa é influente e importante no debate público desde, pelo menos, meados do século XIX, permanecendo vigente neste início do século XXI.

Este artigo revisita o debate do século XIX sobre os papéis respectivos do Estado e da sociedade civil na formação da sociedade pós-revolucionária. O objetivo é, em parte como o

\footnotetext{
2 Faltaria espaço aqui para recuperar todo o debate sobre a relação entre Estado e sociedade civil na historiografia e na teoria política francesa. Para algumas referências de síntese, ver: Aron (1987), Furet (1982) e Lefort (1994).

3 Todas as traduções, quando não indicado o contrário, são de responsabilidade dos autores.
} 
de Rosanvallon, nuançar o que ele chama de "vulgata tocquevilliana". Todavia, isso não será feito por meio de uma reinterpretação da história moderna da França, mas por meio de uma análise do próprio debate teórico do século XIX, a partir do qual buscaremos discutir certas interpretações que enfatizaram de que maneira a constituição da sociedade moderna pressupõe a articulação entre a esfera do Estado - como polo de institucionalização do poder legítimo - e da sociedade civil como espaço da liberdade individual e de constituição de um novo sujeito da legitimidade política, ao mesmo tempo público e privado. A ênfase recairá sobre François Guizot, interpretado aqui como formulador de uma leitura da história francesa e europeia na qual se buscava conciliar a existência de um Estado centralizador e a emergência de uma sociedade civil protagonista da legitimidade política moderna. Como será mostrado, essa interconexão entre Estado e sociedade civil (ou entre o político e o social) era pensada por Guizot como uma via de 112 mão dupla: ao mesmo tempo como chave de compreensão da emergência da moderna civilização europeia e como fundamento da legitimidade política do governo representativo, o regime político adequado a essa nova etapa da civilização.

Este artigo percorrerá as seguintes etapas: (1) exporá uma interpretação do pensamento de Guizot com a qual se estabelecerá um diálogo crítico: aquela desenvolvida por Lucien Jaume em obras como L'individu effacé, ou le paradoxe du libéralisme français ( $\mathrm{O}$ indivíduo apagado, ou o paradoxo do liberalismo francês, em tradução livre), de 1997, e Tocqueville: les sources aristocratiques de la liberté (Tocqueville: as fontes aristocráticas da liberdade, em tradução livre), de 2008. Trata-se de uma interpretação que compreende Guizot como um apologista do Estado centralizado enquanto instância única de instituição da sociedade francesa moderna e de produção da legitimidade no governo representativo. (2) desenvolverá uma linha de interpretação do pensamento de Guizot alternativa à de Jaume: em vez da ênfase na 
unilateralidade do Estado centralizado enquanto instituidor da sociedade francesa moderna e produtor único da legitimidade política nessa sociedade, o que se apresentará aqui será uma evolução histórica paralela do social e do político, da "sociedade civil” burguesa e do Estado monárquico centralizado. O grande "salto" da civilização europeia moderna ocorreria, para Guizot, por meio do encontro e transação entre essas duas instâncias. Após desenvolver essa linha de interpretação do pensamento de Guizot, este artigo contrastará sua obra com outras duas interpretações dos papéis respectivos do Estado e da sociedade civil na formação histórica da moderna sociedade francesa: (3) a desenvolvida pelo autor contrarrevolucionário Louis de Bonald, que critica unilateralmente a possibilidade de uma legitimidade política calcada na esfera da sociedade civil - e vê, portanto, a decadência da civilização europeia no processo em que Guizot via seu progresso; (4) e a desenvolvida por Alexis de Tocqueville, quem também vê o processo louvado por Guizot como uma espécie de decadência, mas por uma razão oposta à de Bonald - em suma, porque o Estado monárquico centralizado teria impedido a formação e a expressão política plena da sociedade civil francesa. Essa comparação permitirá delinear de modo original o lugar de Guizot no pensamento político francês oitocentista: um autor situado entre dois extremos do embate entre Estado e sociedade civil. Se Bonald criticava a formação histórica da moderna sociedade francesa do ponto de vista do Estado pré-revolucionário, e Tocqueville a criticava do ponto de vista da sociedade civil emergente após a Revolução, Guizot procurava conciliar os dois polos e ver a emergência da ordem pós-revolucionária a partir da transação entre Estado e sociedade civil.

\section{Lucien Jaume e a interpretação de Guizot como um "liberalismo pelo Estado"}

Embora o ressurgimento de um interesse intelectual pelo pensamento de Guizot seja um fenômeno relativamente 
recente, tendo como marco o livro Le moment Guizot (O momento Guizot, em tradução livre) de Rosanvallon (1985), sua obra já recebeu, nas últimas décadas, interpretações diversas - e por vezes contrastantes -, especialmente no que se refere a sua interpretação sobre a relação entre Estado e sociedade civil. A interpretação fornecida por Lucien Jaume é paradigmática por ressaltar de modo muito enfático uma suposta primazia conferida por Guizot ao Estado em detrimento da sociedade civil - tanto no modo de teorizar a produção da legitimidade política no governo representativo como no de pensar a formação histórica da moderna sociedade francesa. É por essa razão que a interpretação de Jaume constitui, para o tema deste artigo, uma das principais fontes de diálogo crítico, cabendo expor brevemente as principais linhas dessa interpretação e seus argumentos principais.

Em L'individu effacé (1997), Jaume estabelece uma oposição radical entre duas correntes do liberalismo polí114 tico francês oitocentista: a primeira, ligada historicamente a Madame de Staël e Benjamin Constant, constituiria um liberalismo do sujeito, da consciência ou do indivíduo, e privilegiaria as garantias do indivíduo contra o Estado e seu aparato administrativo; a segunda, ligada a Guizot e aos doutrinários, ${ }^{4}$ constituiria um liberalismo elitista e privilegiaria, ao contrário, "os direitos do poder público, a quem caberia estabelecer as regras de expressão dos direitos individuais

\footnotetext{
4 Os "doutrinários" é o nome que se dá a um grupo de políticos e intelectuais franceses de importância central durante a Restauração (1814-1830) e a Monarquia de Julho (1830-1848) que buscaram conciliar as conquistas da Revolução com a existência de uma monarquia constitucional. Os doutrinários começam a ganhar relevância especialmente a partir de 1816, quando representam a principal força legitimista contra os ultrarrealistas na Câmara, defendendo as prerrogativas do rei contra o parlamento; contudo, é durante a Monarquia de Julho que os doutrinários estarão no centro do poder político francês, representados especialmente por seu principal nome, François Guizot, que ocupará quatro ministérios diferentes durante boa parte do reinado de Luiz de Orleães. Além de Guizot, outros representantes importantes do liberalismo doutrinário foram Royer-Collard, Charles de Rémusat, o Duque de Broglie e Victor Cousin. Para mais informações sobre a história do liberalismo doutrinário na França, ver: Craiutu (2003). Nemoe Petitot (2006) e Rosanvallon (1985).
} 
e, finalmente, sua extensão" (Jaume, 1997, p. 19). Tendo a corrente representada por Guizot exercido uma influência política maior no século XIX (atestada, inclusive, por sua recepção em contextos muito distintos, como o brasileiro, por exemplo, em que a obra de Guizot recebeu importantes interpretações de autores como o Visconde de Uruguai, Evaristo da Veiga, Justiniano José da Rocha, para citar alguns) ${ }^{5}$ justificar-se-ia uma das teses centrais do livro de Jaume: "O liberalismo francês adotou, de modo bastante majoritário, a segunda via, a de um liberalismo pelo Estado, e não contra ou fora do Estado" (Jaume, 1997, p. 11).

$\mathrm{O}$ autor parte de uma das contribuições centrais de Guizot à teoria política - a crítica ao princípio da soberania do povo e a formulação de um princípio concorrente, o da soberania da razão - para estabelecer uma aproximação entre os doutrinários e a corrente contrarrevolucionária, especialmente com Louis de Bonald, a respeito do tema do poder político como emanação da razão divina na Terra. ${ }^{6}$ Apesar da insistência de Guizot sobre a ausência de verdadeira soberania sobre a Terra em razão da falibilidade de toda razão humana, Jaume vê uma confluência entre os doutrinários e Bonald na medida em que aqueles também interpretariam a legitimidade do governo como emanando não da sociedade, mas de uma capacidade maior de conhecer a razão divina: "Nesse novo equivalente do direito divino, o poder talvez não seja infalível, mas é, em todo caso, infinitamente superior aos espíritos fracos em razão" (Jaume, 1997, p. 140). Nessa interpretação, Guizot conceberia o governo como detentor da verdade sobre a sociedade -

\footnotetext{
${ }^{5}$ Para mais sobre a presença de Guizot no Brasil, ver a introdução de José Murilo de Carvalho à obra de Uruguai: Carvalho (2002).

${ }^{6}$ Essa aproximação entre Guizot e os contrarrevolucionários (especialmente Bonald) já havia sido efetuada em Jaume (1992) - artigo que tem por objetivo mostrar a distância da teoria guizotiana da soberania da razão com a filosofia moral kantiana que a inspira em aparência e a proximidade daquela teoria com a escola de pensamento contrarrevolucionária, baseada em uma teoria da imanência do poder à sociedade.
} 
de um saber que, embora tenha origem na sociedade, só se tornaria propriamente verdade na medida em que é recolhido pelo governo, para ser depois difundido de cima para baixo pelo Estado sobre a sociedade.

Tal é, portanto, a chave do liberalismo de Guizot, a qual pode explicar largamente o aspecto altivo, autoritário mesmo, que ele apresenta na prática: o poder eleito, bem eleito, em condições legítimas, é detentor da verdade. É ele que sabe, não a sociedade, a qual espera dele comunicação do saber: descobrir a verdade primeiro, "para fazê-la entrar em seguida nos espíritos”. (Jaume, 1997, pp. 141-143)

Em Tocqueville: les sources aristocratiques de la liberté (2008), Jaume retoma essa interpretação de Guizot como um autor autoritário e estatista, desenvolvendo-a dessa vez a partir do contraste com Tocqueville. Para o intérprete, 116 Guizot e Tocqueville se oporiam radicalmente a respeito de duas questões fundamentais e relacionadas. Em primeiro lugar, sobre o lócus da autoridade na sociedade moderna. Para Guizot, a autoridade viria sempre de cima, das "superioridades naturais" constituídas em poder governamental. Embora elas precisassem do consentimento da sociedade à ação do governo para produzir sua legitimidade, sua autoridade não seria propriamente recebida da sociedade, mas adviria da própria superioridade da aristocracia natural. Tocqueville, ao contrário, pensaria a autoridade do ponto de vista do modelo americano, no qual ela seria exercida de baixo para cima, no âmbito de um povo soberano disperso em poderes locais (Jaume, 2008, pp. 343-354).

Em segundo lugar, os dois autores divergiriam sobre a interpretação da formação histórica da moderna sociedade francesa, especialmente sobre o papel do Estado monárquico centralizado do Antigo Regime, considerado fundamental por ambos. No fundo dessa divergência residiria o 
próprio conceito de sociedade, interpretado de modo diferente por cada autor. Definindo a sociedade pelo "máximo de unidade espiritual e política" (Jaume, 2008, p. 376) a que pode chegar uma nação, Guizot consideraria a sociedade francesa como um fruto da centralização política e administrativa promovida pela monarquia do Antigo Regime, principalmente por Luís XIV. Tocqueville, por outro lado, definindo a sociedade por uma noção de "agir em comum" de fonte ciceroniana, veria na ação do Estado monárquico centralizado, antes, a destruição da sociedade francesa - já que a principal consequência da centralização administrativa excessiva do Antigo Regime teria sido a incapacidade de as diferentes classes agirem conjuntamente (Jaume, 2008, pp. 366-389).

Assim, embora Guizot tenha sempre se apresentado como um partidário da "França nova", resultado da Revolução Francesa, Jaume o interpreta como mais próximo de Bonald do que de Tocqueville. Isso porque a "França nova" seria interpretada pelo doutrinário como um produto do mesmo Estado monárquico centralizado em nome do qual Bonald escrevia, e porque a legitimidade política continuaria, nessa nova sociedade, sendo produzida de cima, pelo Estado detentor da verdade e agregador das "superioridades naturais" (Jaume, 1992; Jaume, 1997; Jaume, 2008). Desenvolveremos, a seguir, uma interpretação diferente do pensamento de Guizot, que dialoga criticamente com os termos colocados pela interpretação de Jaume (especialmente no que concerne à relação entre Estado e sociedade civil) e busca compreender o autor à luz das mesmas comparações: com Bonald e Tocqueville.

\section{Guizot e a transação entre Estado e sociedade}

$\mathrm{Na}$ visão de Guizot, a formação histórica da moderna sociedade europeia pode ser condensada no conceito de civilização. Esse conceito, já bastante trabalhado pela filosofia da história iluminista do século XVIII, da qual 
o doutrinário não deixa de ser um herdeiro, recebe um tratamento original em seu curso de 1828, "A história da civilização na Europa", ao ser imediatamente associado à dinâmica do conflito própria à nova relação entre Estado e sociedade. Como nos lembra Rosanvallon, "a história da civilização de Guizot é uma história do progresso. Mas ela se liga ao desenvolvimento da sociedade e não às transformações do indivíduo" (Rosanvallon, 1985, p. 253). Para Guizot, a moderna civilização europeia é o produto do conflito entre quatro princípios concorrentes de organização política e social: os representados pela nobreza feudal, pela Igreja, pelas comunas e pela realeza. Como apresentado de modo sintético no prefácio à primeira edição de Histoire de la révolution d'Angleterre (História da revolução da Inglaterra, em tradução livre), de 1826, cada um desses quatro atores históricos teria fornecido uma contribuição importante ao desenvolvimento da civilização europeia 118 (cf. Guizot, 1845, pp. 9-17). Se a Alta Idade Média e o período áureo do feudalismo teriam concentrado as contribuições da nobreza feudal e da Igreja, a Baixa Idade Média e o início da era moderna teriam sido marcados pelas contribuições decisivas das comunas e da realeza.

O feudalismo é interpretado por Guizot como a primeira forma regular alcançada pela civilização europeia após os cinco séculos de caos que teriam se seguido à queda do Império Romano do Ocidente. A sociedade feudal é caracterizada como "o único meio encontrado pelos homens para sair enfim da barbárie, mas sociedade fraca e incapaz de engendrar um verdadeiro governo" (Guizot, 1844, p. 338). Apesar desse caráter fraco e incipiente da sociedade feudal, o autor se esforça para abordá-la a partir do que ele chama de "o ponto de vista social" (Guizot, 1985, p. 127). Esse ponto de vista busca compreender historicamente como a esfera do social vai lentamente se emancipando do Estado e tornando-se um novo sujeito político da civilização 
europeia, impondo limites a esse último. A contribuição da sociedade feudal para o progresso da civilização se mediria, assim, por quanto sua ação histórica teria colaborado para a limitação do poder político e para a constituição de seu caráter público. Guizot historiciza, desse modo, a questão do "garantismo" liberal, relacionando-a estreitamente ao problema da necessidade da garantia do direito como uma forma de proteção do social do domínio do político. Qual teria sido o direito político engendrado pela sociedade feudal para protegê-la da ação opressiva do poder?

O único direito político que o regime feudal tenha sabido fazer valer na sociedade europeia é o direito de resistência: não digo da resistência legal; não se podia tratar de resistência legal em uma sociedade tão pouco avançada. O progresso da sociedade é, precisamente, substituir as vontades particulares pelo poder público e a resistência individual pela resistência legal. [...] sob o feudalismo, não havia lugar para nada parecido. $O$ direito de resistência que o regime feudal sustentou e praticou é o direito de resistência pessoal: direito terrível, insociável, pois ele apela à força, à guerra, o que é a destruição da própria sociedade [...]. É a honra da civilização tornar esse direito inativo e inútil; é a honra do regime feudal tê-lo constantemente professado e defendido. (Guizot, 1985, pp. 127-128)

Assim, um direito rudimentar de se proteger da ação arbitrária do poder político seria uma contribuição incipiente da sociedade feudal, embora essa sociedade e esse direito precisassem ainda passar por um longo desenvolvimento histórico para atingir uma forma mais madura e menos precária. Nela, o poder se confundiria com a mera força, o que faria o próprio direito da sociedade contra o poder assumir também a forma da força, ou da resistência pessoal em vez da legal. 
A primeira experiência de um poder legitimado pela razão constituiria, para Guizot, a principal contribuição de um segundo elemento formador da civilização europeia: o cristianismo. A constituição de uma ecclesia, de uma comunidade religiosa cristã, seria fruto da adesão dos indivíduos à verdade revelada por Cristo que se daria não pela coerção, mas "pela busca, pela predicação, pelo ensinamento das verdades religiosas" (Guizot, 1985, p. 138). Diferentemente do elemento religioso encontrado nas sociedades antigas, que se impunha externamente aos indivíduos, condicionando a vida social e política, "o governo religioso decorre, naturalmente, da sociedade religiosa" (Guizot, 1985, p. 138, grifos dos autores). A Igreja teria, desse modo, estabelecido o princípio de um governo que não é fundado na força ou na coerção, tampouco na vontade, mas na criação de um sistema de meios e de poderes que possibilitassem "a descoberta da verdade que tem o direito de governar a sociedade, para fazê-la entrar 120 nos espíritos e ser adotada voluntariamente, livremente" (Guizot, 1985, p. 137). Enfim, ao estudar a contribuição da Igreja para o desenvolvimento da civilização europeia, Guizot estabelece o que ele entende como "os princípios básicos da legitimidade política”, ausentes no simples princípio feudal. Conceitos como verdade, razão e capacidades aparecem como elementos constitutivos da legitimidade do poder sustentada por meios "puramente morais". Não haveria legitimidade na força, na coerção ou na vontade, mas apenas na ação política que visa convencer as "inteligências" e as "vontades livres" de uma verdade racional.

O terceiro elemento - ao lado do regime feudal e da Igreja - que Guizot estudará como fundamento da civilização é o ressurgimento das cidades como centro da vida social e política europeia. $\mathrm{O}$ autor atribui à emancipação das comunas medievais, a partir dos séculos XI e XII, o nascimento da burguesia - "A formação de uma grande classe social, da burguesia, era o resultado necessário da 
emancipação local dos burgueses" (Guizot, 1985, p. 181) e a eclosão da luta de classes: "O terceiro grande resultado da emancipação das comunas é a luta das classes, luta que preenche a história moderna. A Europa moderna nasceu da luta das diversas classes da sociedade" (Guizot, 1985, p. 182). ${ }^{7}$ Esse movimento de disputa entre classes no qual nenhuma consegue o controle completo sobre as outras é entendido como "causa de progresso" (Guizot, 1985, p. 182). É no próprio conflito, na variedade dos interesses e paixões que movem as classes, que Guizot encontra a fonte de uma dinâmica histórica que conduziria à "aculturação" da liberdade pública na Europa moderna. Contudo, a luta de classes tornaria cada vez mais patente a necessidade da constituição de uma ordem, de uma unidade mínima que garantisse a própria existência da diversidade. Assim, se é do renascimento da ordem comunal que a liberdade e o conflito tomam sua forma social moderna, seria com a superação de seu caráter fragmentário que a ordem política se identificaria com a criação de uma unidade.

A necessidade de uma ordem que imperasse sobre o conflito teria conduzido ao nascimento de "certo espírito geral, certa comunidade de interesses, de ideias, de sentimentos que triunfaram sobre a diversidade e a guerra" (Guizot, 1985, p. 182). Teria sido a necessidade de certa "existência social comum" que teria originado a unidade nacional na Europa. É apenas a partir da constituição dessa unidade nacional que se poderia, para Guizot, falar propriamente em uma sociedade moderna, na qual os antigos elementos constitutivos da civilização (a nobreza feudal, a Igreja, as comunas e a realeza), antes atuando e combatendo como forças privadas,

\footnotetext{
7 Até onde se sabe, Guizot é o "pai" da expressão "luta de classes" - conceito cuja invenção nunca foi reivindicada por Marx. Em carta a Weydemeyer, de 1852, o autor alemão remete a teorização da luta de classes a "historiadores burgueses" como Augustin Thierry e Guizot (Marx e Engels, 1983, p. 61). Sobre as diferenças no modo como Guizot e Marx entendiam a luta de classes, ver: Freller (2015, p. 32, nota $41 ; 2016$, p. 183.
} 
encontrar-se-iam agora reduzidos a duas forças públicas: o povo e o governo. "A ação de um poder geral sobre o país todo, a influência do país sobre o poder que o governa, aí está a sociedade, eis a história: as relações entre essas duas grandes forças, sua aliança ou sua luta, eis o que a história descobre, o que ela conta" (Guizot, 1985, p. 192).

O ponto a reter é que esse movimento de unificação, de emergência de uma unidade nacional, que inauguraria a sociedade propriamente moderna ao reduzir os antigos elementos da civilização às duas forças públicas do povo e do governo, não poderia resultar apenas do movimento de emancipação comunal e de suas consequências - a sociedade burguesa, a luta de classes e a aculturação da liberdade. A maior expressão do movimento de emancipação comunal teria sido a organização republicana das cidades italianas do Renascimento, que, segundo Guizot, "não continha em si mesma, nessa época, o princípio do progresso, da duração, da extensão, não tinha 122 futuro" (Guizot, 1985, p. 231) - e isso justamente devido à impossibilidade de gerar uma unidade nacional em uma época em que "a sociedade ainda não era suficientemente avançada para se prestar à unidade; tudo ainda era local demais, especial demais, estreito demais, diverso demais nas existências e nos espíritos" (Guizot, 1985, p. 236).

O movimento de unificação referido acima teria sido a contribuição principal do quarto grande elemento constitutivo da civilização europeia - a realeza - e da obra centralizadora empreendida por ela a partir do século XV. A centralização monárquica cumpre um papel eminentemente progressista na história da civilização europeia de Guizot, aparecendo como a principal responsável pela emergência de um poder público e de uma opinião pública no seio de uma sociedade em que tudo tendia ainda à fragmentação e ao predomínio do local e do particular sobre o geral e o público.

Essa retomada da evolução histórica europeia teorizada por Guizot permite observar o modo como ele entendia a 
relação entre Estado e sociedade na gênese da civilização moderna. Em certo sentido, a sociedade precede, para ele, a existência do Estado centralizado. O reino da liberdade e do conflito constitutivos do social dataria historicamente da emancipação das comunas medievais, ocorrida em uma época anterior ao movimento de centralização e unificação que permitiria a emergência de um poder público a partir do século XV. No entanto, seria apenas com a ascensão do Estado (primeiramente sob a forma monárquica e centralizada) que esse social poderia adquirir seu caráter civil, ligado a um ambiente de unidade nacional e à redução dos elementos constitutivos da civilização às duas forças públicas do povo e do governo, o que é característico da sociedade propriamente moderna.

A sociedade moderna seria, assim, resultado da transação entre a sociedade burguesa das comunas - reino da liberdade e do conflito - e a necessidade de um poder público legítimo, de uma garantia institucional, frutos da centralização monárquica. Na interpretação do pensamento de Guizot aqui desenvolvida, a sociedade moderna não é instituída unilateralmente pelo Estado monárquico centralizado, como o é na interpretação de Jaume retomada anteriormente neste artigo. Pelo contrário, ela é o fruto de um encontro e de uma transação entre duas instâncias que se desenvolvem paralelamente na evolução histórica da civilização europeia: o social e o político. O social teria uma primeira forma rudimentar já na sociedade feudal, mas seus princípios básicos datariam da emancipação das comunas e da constituição da burguesia como classe social. O político se constituiria por meio do movimento da centralização monárquica, mas sua legitimidade estaria intrinsecamente ligada à retomada de princípios que já orientavam a organização da Igreja desde os primórdios da Idade Média.

Evidentemente, os princípios de legitimação do poder que Guizot havia encontrado na constituição da Igreja deveriam ser repensados em um novo contexto no qual eles 
adquiririam uma forma mais madura: o do governo representativo moderno, entendido como a principal conquista da Revolução Francesa sobre o Estado monárquico absoluto e centralizado que a precedeu. É importante destacar que o autor entende a Revolução Francesa como fruto de um desencontro entre "uma sociedade em grande desenvolvimento de riqueza, de força, de atividade intelectual de todo gênero" e "um governo essencialmente estacionário, não possuindo nenhum meio de se renovar, de se adaptar ao movimento de seu povo" (Guizot, 1985, p. 300). Nesse ponto ele retomava um célebre diagnóstico já enunciado por Benjamin Constant, em 1797, em seu panfleto Des réactions politiques (Das reações políticas, em tradução livre), segundo o qual "no momento em que o acordo entre as instituições e as ideias é destruído, as revoluções são inevitáveis" (Constant, 1964, p. 27). Se, até e durante o reinado de Luís XIV, o Estado monárquico centralizado havia cumprido um papel importante na unificação, 124 regularização e estabilização da sociedade, após a morte de Luís XIV a sociedade teria passado a representar o progresso e o governo, o atraso - sendo a Revolução Francesa compreendida como uma revanche da sociedade e uma forma (violenta) de adequação das instituições políticas a ela.

Essa "sociedade em progresso" de onde teria partido o impulso para a Revolução Francesa seria também a fonte da legitimidade no novo ordenamento político conhecido como governo representativo. É verdade que essa legitimidade política não é teorizada em uma chave democrática, mas elitista: o governo representativo não é pensado como um instrumento para viabilizar a soberania do povo, a qual Guizot considerava como um princípio simplesmente falso, mas para permitir a identificação e a elevação ao governo das chamadas "superioridades naturais" espalhadas pelo social. ${ }^{8}$

\footnotetext{
8 A distinção entre governo representativo e democracia está formulada em Manin (1997).
} 
Assim, o sistema de participação e representação evocado por Guizot está condicionado por algo que Rosanvallon chama de "ordem capacitária", ${ }^{9}$ uma norma que ambiciona estabelecer os "limites naturais" da política definindo, através da lei eleitoral, certas capacidades que devem ser condição do direito à participação. A ordem capacitária é a solução prática para aplicar a razão pública ao sistema político.

Contudo, o ponto a ressaltar é que essas superioridades só são consideradas legítimas na medida em que se destacam no plano social antes de ascenderem ao poder político. A aristocracia do Antigo Regime havia se tornado falsa justamente porque havia fixado seus privilégios no plano político sem se destacar mais no plano da sociedade, onde a verdadeira superioridade estava com a burguesia. Daí a necessidade da Revolução Francesa. Em Des moyens de gouvernement et d'opposition dans l'état actuel de la France (Dos meios de governo e de oposição no estado atual da França), de 1821, Guizot chega a pregar que o Estado francês desenvolva, no contexto pós-revolucionário em que escreve, uma estrutura mais capilar e descentralizada, a fim justamente de identificar as "superioridades naturais" que se destacariam na sociedade e permitir sua ascensão ao governo via poderes locais, de modo que elas pudessem em algum momento chegar até mesmo ao poder central. O resultado da excessiva centralização administrativa do Estado francês seria departamentos e localidades repletas "de influências perdidas, de superioridades sem emprego" (Guizot, 1987, p. 228), ao passo que o governo central, isolado da sociedade, não estaria recrutando a verdadeira aristocracia natural. Como se vê, se Guizot considera como fundamental o papel histórico da centralização monárquica para a constituição da forma política do Estado moderno,

\footnotetext{
9 Rosanvallon, em seu estudo clássico sobre os doutrinários, Le moment Guizot, retraça longamente o problema da ordem capacitária no pensamento de Guizot e seus contemporâneos. Para informações adicionais, ver também: Rosanvallon (2000, capítulo 3).
} 
principalmente no período em que a sociedade ainda era frágil e incapaz de alcançar sozinha um estado de unidade e generalidade, essa mesma autonomia do Estado em relação à sociedade não é mais considerada como necessária no contexto pós-revolucionário, em que a sociedade teria condições de extrair de si mesma seu próprio governo. Nesse novo contexto, a excessiva centralização administrativa legada pela monarquia do Antigo Regime aparece como um empecilho, como uma forma de isolar o poder político de sua fonte de legitimidade - a sociedade. ${ }^{10}$

A sociedade não seria apenas a fonte, a origem, da legitimidade política, mas também seu destinatário. Ou seja, o poder legítimo não seria apenas aquele que tem origem em uma superioridade surgida no âmbito da sociedade, mas também aquele que presta contas e prova constantemente sua legitimidade a essa sociedade, deixando de constituir um poder quando essa prova não é mais considerada suficiente (daí a centralidade do problema da opinião pública no pensamento de Guizot e dos liberais). ${ }^{11}$ Enfim, a relação entre sociedade e poder político adequada ao governo representativo é sintetizada por Guizot no seguinte parágrafo de Des moyens de gouvernement:

Eis todo o segredo das revoluções, todo o objeto dos governos livres. É, em particular, o objetivo último e o princípio fundamental do governo representativo. Ele se propõe precisamente a estabelecer entre a sociedade e o poder sua relação natural e legítima, ou seja, a impedir que o poder permaneça de direito onde ele não está mais de fato,

\footnotetext{
10 "Fala-se muito da centralização, da unidade administrativa. Ela prestou imensos serviços à França. Conservaremos muitas de suas formas, de suas regras, de suas máximas, de suas obras; mas o tempo de sua soberania passou. Ela hoje não é mais suficiente para as necessidades dominantes, para os perigos urgentes de nossa sociedade" (Guizot, 1849, p. 119).

11 Para mais sobre o tema da opinião pública na obra dos liberais franceses, ver Cassimiro (2018).
} 
a fazê-lo cair constantemente nas mãos das superioridades reais e capazes de exercê-lo segundo sua destinação. As câmaras, a publicidade dos debates, as eleições, a liberdade de imprensa, o júri, todas as formas desse sistema, todas as instituições vistas como suas consequências necessárias têm por objetivo e por resultado escrutinar sem cessar a sociedade, jogar luz sobre as superioridades de todo gênero que ela contém, trazê-las ao poder, e, após tê-las nele estabelecido, obrigá-las a merecê-lo sob pena de perdê-lo, forçando-as a empregá-lo apenas publicamente e por vias acessíveis a todos. Sistema admirável, pois ele é conforme à verdade das coisas, pois ele resolve o problema da aliança do poder com a liberdade; por um lado, concedendo o poder apenas à superioridade, e, por outro, impondo à superioridade a lei de se provar a si mesma, de se fazer constantemente aceitar. (Guizot, 1987, pp. 157-158)

Assim, a chave pela qual Guizot compreende a emergência histórica da moderna sociedade francesa e europeia é a da transação entre a sociedade civil e o Estado. É de modo semelhante que o autor interpreta a produção da legitimidade política nessa sociedade: se o poder político é necessário para reduzir a pluralidade da sociedade a uma unidade, ele só é legítimo se está em conexão íntima com a sociedade, tendo ela como sua fonte e seu destinatário. O significado dessa transação entre Estado e sociedade civil proposta por Guizot no debate geral do século XIX ficará mais claro no contraste com as interpretações de Bonald e de Tocqueville.

\section{Bonald e a crítica teológico-política da sociedade civil burguesa}

A perspectiva de Bonald interessa aqui por partir de um ponto consideravelmente diferente: o processo político no qual tanto a França quanto o restante da Europa mergulham na modernidade não seria fruto do progresso histórico, mas 
de uma ruptura cujas causas são fundamentalmente teológicas. Seu magnum opus, a Théorie du pouvoir politique et religieux (Teoria do poder político e religioso, em tradução livre), de 1796, e as análises conjunturais, especialmente sobre a Revolução de 1830, combinam-se em um diagnóstico que apontará a ruptura revolucionária como epítome de um processo de destruição da soberania e da organização hierárquica da sociedade, cuja divisão funcional vai aos poucos sendo substituída pelo primado do indivíduo e a consequente dissolução dos fundamentos da vida comum.

Bonald parte, assim como os demais teóricos da teologia-política, ${ }^{12}$ de uma crítica à filosofia moderna como um todo - mas, em especial, à filosofia do direito natural, na medida em que essa teria ignorado que a verdade não é simplesmente o resultado da consciência filosófica correta, ato puro do indivíduo-autoconsciente, mas a realização histórica e social do homem no Estado e na religião. A filosofia 128 política só alcançaria seu caráter efetivo quando descesse da especulação lógica e encontrasse na realidade a necessidade racional da identidade entre verdade e sociedade, ou "a identidade entre Deus e a história" (Spaemann, 2002, p. 18). No fundo, o autor se opõe à distinção entre natureza racional/individual e natureza social, a qual fundamentaria tanto o jusnaturalismo como o racionalismo cartesiano. Em sua perspectiva, a consciência humana só poderia ser pensada a partir da linguagem, um fenômeno de natureza fundamentalmente social. Somente a língua tornaria o homem um ser pensante e, em consequência, sua consciência só poderia se constituir na sociedade e na história e ser compreendida a partir delas.

\footnotetext{
12 Preferimos classificar tais autores como "filósofos da teologia-política" e não como reacionários ou mesmo contrarrevolucionários, pois as últimas duas expressões podem implicar uma confusão entre categorias históricas e classificação teórica, ou seja, elas impõem uma abrangência de autores e atores que não necessariamente estão vinculados à teoria da soberania teológica, como Chateaubriand, por exemplo. A referência aqui é, evidentemente, a obra de Carl Schmitt (Schmitt, 2006).
} 
Assim, a sociedade seria a forma da "conservação" do homem; seria nela que o homem encontraria sua essência racional. Todavia, ela só se realizaria efetivamente como parte da unidade entre Estado e religião. É a partir dessa lógica que Bonald mobiliza o conceito de sociedade civil (société civile) como expressão da participação do homem na civis, na unidade entre soberania (Estado) e comunidade (religião cristã). A condição colocada por Guizot para o progresso da civilização é a necessidade da recuperação do caráter público do Estado, que se reencontraria com uma sociedade livre e ativa na determinação do poder. Bonald a encontra na unidade indissolúvel entre natureza política e natureza sacra: a verdadeira condição natural do homem - a civilização se realizaria no encontro entre a religião revelada e o poder soberano (Bonald, 1859, T. III, p. 134). A própria ideia de povo - e, portanto, de sociedade - só teria sentido no seio de um poder soberano, já que seria o corpo soberano que daria ao povo sua identidade e o sentido de participação em uma unidade que o precederia. A sociedade, como realização da razão natural, teria como condição a exclusão da vontade humana no ato de sua constituição. $\mathrm{O}$ autor reitera, assim, a impossibilidade lógica de um poder constituinte que se realizaria pelo povo. O povo só se tornaria realidade em uma comunidade organizada por um Estado - um poder soberano unido à verdade da religião revelada.

Bonald se encontra com a teoria da soberania de Joseph de Maistre, especialmente como explicitada na introdução de uma de suas obras finais, Du pape (Do papa, em tradução livre), de 1819, na qual o poder soberano dos reis é apresentado como uma força transitória e intermédia, submetida ainda por outra força soberana: o papado. No limite, o poder soberano seria aquele que "governa e não é governado, julga e não é julgado" (Maistre, 1819 apud Armenteros, 2011, p. 123). Assim, de Maistre apresentará a história da Europa até o advento do protestantismo como a ação da soberania papal 
na constituição e na arbitragem das soberanias reais, o que resultaria na constituição das nações europeias. Em termos mais gerais, Bonald afirmará que a civilização não é outra coisa senão a aplicação da religião cristã na constituição de uma sociedade civil, o que o leva à conclusão de que "A Europa é a única sociedade civil do universo" (Bonald, 1859, p. 317).

A raiz da ruptura revolucionária que abalaria essa ordem tradicional estaria na Reforma Protestante, entendida como a revolta do indivíduo egoísta contra a autoridade e a moral constituídas. A Reforma teria produzido a grande cisão na civilização europeia, fundada na "unidade da religião e da autoridade", ao consagrar um "povo da pluralidade e do sentido privado" (Bonald, 1988, p. 49). Essa ruptura teria resultado na criação de duas constituições políticas possíveis: a constituição monárquica, fiel ao princípio da autoridade e da unidade religiosas, e a democrática, realização do reino do indivíduo como critério moral criado pelo protestantismo (Bonald, 130 1988, p. 49). Esses dois princípios de organização política são evocados por Bonald em suas obras de análise "conjuntural", especialmente nas suas Réflexions sur la révolution de Juillet 1830 (Reflexões sobre a revolução de julho de 1830, em tradução livre), na qual o autor critica veementemente o projeto do liberalismo político de manter a autoridade monárquica limitada e em convivência com um regime parlamentar e constitucional. Para demonstrar a inviabilidade do projeto liberal (ao qual Bonald associa a palavra "democracia”, não reivindicada pelos próprios liberais), o autor distingue a monarquia real da monarquia popular, aquela fruto da carta constitucional enquanto a primeira encontraria sua legitimidade no caráter soberano e indissolúvel da figura real e na existência de meios de governo que teriam origem na própria soberania, a segunda, fruto de um "misto entre monarquia e democracia" (Bonald, 1988, p. 46), deveria governar em um contexto no qual a dissolução dos meios de governo entre diversas forças sociais tornaria a existência da autoridade real inútil. 
No fundo, Bonald está criticando a ideia de que o poder soberano possa compartilhar sua legitimidade com uma esfera que existiria independente dele. Para o contrarrevolucionário, a sociedade não é senão o espaço do interesse e da ambição, de modo que sua interferência no exercício do poder destruiria a função pública do Estado. A divergência com a concepção de sociedade de Guizot não poderia ser maior. Se ambos partem da ideia de que é a formação de um Estado soberano que dá origem à dimensão pública do poder na modernidade, Bonald, contudo, diverge totalmente da ideia de que a legitimidade do poder político possa ter origem na esfera da sociedade. Sem citar Guizot, o autor das Réflexions sur la révolution de Juillet 1830 ataca diretamente a concepção de uma representação "capacitária" de seu contemporâneo, negando que o poder político possa pertencer legitimamente às classes que o doutrinário via como as "superioridades naturais" da nova sociedade. Critérios "literários, comerciais, industriais, geométricos, químicos, administrativos etc.” não poderiam ser confundidos com capacidades políticas: esses critérios não seriam senão a racionalização da confusão entre sociedade doméstica e sociedade pública, entre o público (encarnado pelo soberano) e o privado (Bonald, 1988, p. 71).

Assim, a emergência da moderna sociedade civil burguesa, no interior da qual Guizot via a origem de um novo poder político legítimo, era vista por Bonald como uma ameaça à ordem política legítima. Como o doutrinário, o autor contrarrevolucionário insere o legado da Revolução Francesa no contexto mais amplo do continuum da história europeia. Contudo, essa longue durée não é vista por ele como o resultante de um conjunto de fatores que apontam para o progresso da civilização, mas para sua inevitável decadência; essa decadência estaria ligada à ascensão de uma sociedade que não derivaria mais da submissão incondicional ao poder soberano unido à religião verdadeira, mas que, ao contrário, tentaria submeter o poder 
político a sua própria lógica individualista e mercantil, portadora de caos e dissolução dos laços sociais.

\section{Tocqueville: 0 individualismo e o Estado moderno}

O contraste entre Guizot e Bonald, estabelecido previamente, diferencia a interpretação desenvolvida aqui da de Jaume que, por sua vez, aposta em uma proximidade entre o doutrinário e o contrarrevolucionário a respeito da primazia do Estado como produtor da legitimidade política e instituidor da sociedade. Resta estabelecer o lugar de Tocqueville nesse debate do século XIX, já que a interpretação de Jaume sobre a posição de Guizot não postula apenas sua proximidade com Bonald, mas também sua distância com o autor de $O$ antigo regime e a revolução.

O fato de que a última obra de Tocqueville representava uma interpretação da história francesa em certa ruptura com as lições históricas de Guizot, as quais haviam tido um papel

132 importante na formação intelectual do jovem descendente da aristocracia normanda, foi percebido em primeiro lugar pelo próprio doutrinário, que escreve logo após a publicação do livro, em carta a Tocqueville datada de 30 de junho de 1856:

Eu reencontro em seu livro o mesmo caráter que me impressionara em sua grande obra sobre os Estados Unidos da América. O senhor pinta e julga a democracia moderna como um aristocrata vencido e convencido de que seu vencedor tem razão. Talvez o senhor tenha pensado com demasiada frequência na aristocracia histórica que foi realmente derrotada, e não o suficiente na aristocracia natural que não pode nunca ser vencida por muito tempo e termina sempre retomando seus direitos. Talvez, se o senhor as tivesse distinguido mais constantemente, o senhor teria ficado mais à vontade para contestar à democracia, mesmo aceitando-a, o que há de ilegítimo e insociável em sua vitória. (Guizot, 1956 apud Tocqueville, 1989, p. 343, nota 12) 
Por esse comentário, nota-se que a divergência entre Guizot e Tocqueville remontava já a A democracia na América, como apontado pelo próprio doutrinário. O que incomoda Guizot na obra de Tocqueville desde a década de 1830 é o fato de seu antigo aluno radicalizar tanto o que seria o impulso igualitário característico das sociedades modernas que sua análise dessas não ofereceria espaço ao que seria a "aristocracia natural" da nova sociedade. Como Guizot, Tocqueville pensava o poder político moderno como emanando da nova forma de sociedade que havia substituído a sociedade feudal. Porém, o que se destacaria nessa nova sociedade não seria uma nova aristocracia natural, associada por Guizot à burguesia, mas um impulso radical rumo à igualdade, de modo que não haveria mais alternativas políticas à soberania do povo rechaçada pelo doutrinário. Não à toa, Guizot considera Tocqueville como "um aristocrata vencido e convencido de que seu vencedor tem razão" (Guizot, 1956 apud Tocqueville, 1989, p. 343).

No entanto, o que interessa no contexto deste artigo é a análise de Tocqueville sobre a derrota daquilo que Guizot chama de "aristocracia histórica", ou seja, a classe dirigente do Antigo Regime. Para Guizot, a derrota definitiva dessa “aristocracia histórica” pela Revolução Francesa havia representado um grande progresso, justamente porque essa falsa aristocracia havia sido substituída pela "aristocracia natural" produzida pela nova sociedade burguesa, que teria o verdadeiro direito de governar. Na obra de Tocqueville, ao contrário, o tom é muito mais pessimista: a "aristocracia histórica" não teria sido substituída por uma "aristocracia natural", como bem percebe a leitura de Guizot; sua derrota seria apenas o coroamento de um processo muito mais longo de dissolução dos laços sociais e políticos que produziam a ordem hierárquica feudal, sem que uma nova classe capaz de instituir um governo livre tivesse emergido desse processo. Nesse sentido, o tom pessimista com que 
essa dissolução social é percebida, unido ao ceticismo em relação ao governo das classes médias defendido por Guizot como o grande resultado da Revolução Francesa, aproxima a abordagem de Tocqueville da de Bonald: sob pontos de vista diferentes, ambos criticam o processo histórico celebrado por Guizot como uma espécie de decadência.

Interessa, entretanto, insistir no contraste entre os pontos de vista de Bonald e Tocqueville, pois ele é muito significativo. Bonald, como vimos, critica o processo de formação da sociedade moderna sob o ponto de vista do Estado monárquico centralizado unido à religião cristã, cuja soberania teria sido rompida pelo individualismo criado pela Reforma Protestante. A sociedade civil teria se dissolvido porque ela só poderia ser instituída por um Estado soberano em união com a religião verdadeira, tendo se fragmentado quando essa soberania foi posta em questão. Tocqueville, por sua vez, critica o processo de formação da sociedade 134 francesa moderna sob um ponto de vista contrário: seu alvo é justamente o Estado monárquico hipercentralizado, que teria fragmentado a sociedade e impedido sua emergência como protagonista do novo "Estado social" pós-revolucionário. Em O Antigo regime e a revolução (2009), Tocqueville se defronta com o problema central de Bonald, de Maistre e demais autores da teologia-política, o individualismo ${ }^{13}$ identificando-o na fragmentação e dissolução da sociedade francesa nos últimos séculos do Antigo Regime:

Nossos pais não tinham a palavra individualismo, que forjamos para nosso uso, porque no tempo deles de fato não havia indivíduo que não pertencesse a um grupo e que pudesse se considerar absolutamente só; mas cada um dos mil pequenos grupos de que a sociedade francesa se compunha só pensava

\footnotetext{
13 Cristina Cassina aponta que a própria palavra individualismo (individualisme) é atribuída a Joseph de Maistre pelo Barão de Frénilly (Cassina, 2007, p. 19).
} 
em si mesmo. Era, se posso expressar-me assim, uma espécie de individualismo coletivo, que preparava as almas para o verdadeiro individualismo que conhecemos hoje. (Tocqueville, 2009, p. 107; grifos do autor)

Não obstante, para Tocqueville, o individualismo não seria, como para Bonald, o fruto de uma rebelião do indivíduo consagrado pela Reforma e pela filosofia do direito natural contra o Estado soberano. Ao contrário, ele seria um produto do próprio Estado monárquico hipercentralizado e sua estratégia de neutralizar a influência política que a sociedade exercera até o século XIV por meio dos "corpos intermediários", instituições como os estados gerais e provinciais, que teriam sido capazes de unir nobres e plebeus na deliberação sobre os assuntos comuns. Seria essa estratégia de neutralização da influência política da sociedade que explicaria o

zelo incessante em manter as classes apartadas umas das outras, para não poderem reaproximar-se nem se associar em uma resistência conjunta e o governo nunca tivesse de lidar ao mesmo tempo com mais do que um número muito pequeno de homens separados de todos os outros. (Tocqueville, 2009, p. 117)

Assim, Tocqueville escreve do ponto de vista da sociedade, e Jaume tem razão quando aponta que o conceito de sociedade em Tocqueville está ligado a uma noção ciceroniana de agir em comum. Como Bonald, ele lamenta a destruição da antiga sociedade francesa, mas culpa por essa destruição o agente que o contrarrevolucionário entendia como o responsável por sua conservação: o Estado monárquico soberano e centralizado. Com esse diagnóstico, o autor de $O$ Antigo regime e a revolução se afasta também de Guizot e de sua interpretação de uma transação entre Estado e sociedade civil para a produção da moderna sociedade francesa. 
Em sua visão, o Estado monárquico centralizado não teria transacionado com a sociedade civil em formação, mas teria antes a fragmentado e mesmo destruído. Cabe destacar que tanto Guizot como Tocqueville eram críticos dos efeitos da centralização administrativa excessiva na França do século XIX. Porém, para Guizot, a centralização monárquica teria cumprido um papel progressista importante naquele período (entre os séculos XV e XVII) em que a sociedade civil ainda não estava totalmente formada e precisava de um impulso unificador. Para Tocqueville, ao contrário, a centralização monárquica teria tido, desde o século XV, um efeito nocivo, na medida em que teria sufocado os espaços políticos de associação entre as diferentes classes e de expressão política da sociedade, levando à sua dissolução. Daí as visões contrastantes sobre a sociedade que fez a Revolução Francesa. Para Guizot, tratava-se de uma sociedade em pleno progresso e já unificada em torno de uma nova aristocracia natural 136 portanto pronta para erigir uma nova forma de governo livre. Para Tocqueville, essa sociedade mal existia mais como coletividade, como espaço de agir em comum; havia apenas invejas e ódios causados por séculos de separação, sem que houvesse cimento para a construção de um governo livre:

Quando as diversas classes que partilhavam a sociedade da antiga França entraram novamente em contato, há sessenta anos, depois de estarem isoladas durante tanto tempo por tantas barreiras, inicialmente só se tocaram em seus pontos doloridos e só se reencontraram para se dilacerarem mutuamente. Mesmo em nossos dias suas invejas e seus ódios lhes sobrevivem. (Tocqueville, 2009, p. 118)

\section{Considerações finais}

Assim, as interpretações de Bonald e de Tocqueville sobre a formação histórica da moderna sociedade francesa 
permitem situar melhor a interpretação de Guizot, conduzida primordialmente pela noção de progresso. Céticos em relação ao progresso da civilização europeia celebrado por Guizot, Bonald e Tocqueville são, antes, críticos do processo de formação dessa sociedade: o primeiro critica esse processo do ponto de vista do Estado monárquico e teocrático cuja soberania teria sido negada pelo individualismo da Reforma e dojusnaturalismo; o segundo critica esse mesmo processo do ponto de vista da sociedade sufocada pelos excessos da centralização administrativa e pela eliminação dos espaços de deliberação comum entre as diferentes classes. É o esforço de ler esse processo histórico pela chave da noção de progresso que leva Guizot a recusar uma escolha entre o ponto de vista da sociedade ou do Estado: se essa História for mesmo progressista, tanto a sociedade quanto o Estado precisariam ter dado sua contribuição.

A razão pública - instrumento imaginado por Guizot para proceder a mediação entre a sociedade e o Estado e a seleção de elites governantes - só pode emergir se a sociedade obedecer a alguns princípios que não são outros senão os da liberdade política, e essa é fruto de um processo histórico cumulativo que se realiza na modernidade tal como ele nos apresenta em sua História da civilização na Europa. Porém, o reconhecimento da realização histórica da liberdade não é nunca pensado apenas na chave do exercício de um direito individual - como para o "liberalismo do sujeito", nas palavras de Lucien Jaume (1997, pp. 25-117) -, mas sempre com relação à capacidade dos atores políticos de se apropriarem das forças do social na criação de consensos. Assim, Guizot irá estabelecer uma diferença substantiva entre a razão pública e a opinião que resulta de "preconceitos" sociais, negando que exista uma diferença substantiva entre opiniões e interesses. Na medida em que as opiniões se apresentam, cabe ao político saber governá-las e conduzi-las, sem distinguir se são originadas em uma convicção 
ou em um interesse. Sendo assim, a origem da opinião não importa; é preciso reconhecer que o social é composto de uma diversidade incontável de "expressões comuns" e "frases vulgares" que, no entanto, nos permitem compreender o "instinto público" (Guizot, 1886, pp. 138-139). Guizot designa como "instinto público" a opinião vulgar das massas, tudo aquilo que, sem se sustentar pelo exame criterioso da razão, serve como meio de expressar um desejo político; são opiniões herdadas do passado ou da apreensão impressionista de debates filosóficos que se convertem em convicções políticas. O problema, então, é saber como o poder deve lidar com a opinião - esse resultado da sociedade nova que emerge da dissolução da ordem hierárquica do Antigo Regime, e como ele deve tomá-la como meio, e não como adversário, do governo. Dito de outro modo, governar a partir da razão pública significa também governar com os instintos públicos que caracterizam o residual, a pluralidade 138 do ambiente criado pela liberdade pública na nova sociedade que um novo governo legítimo, constituído pela razão pública, precisará governar.

A sociedade moderna implica, portanto, uma nova relação entre governo e opinião, entre o corpo coletivo e as garantias dos indivíduos, Estado e sociedade. Poderíamos, a princípio, dizer que, ao encarar a diversidade de opiniões políticas não como um espaço de busca de consensos, mas como um instrumento a ser capturado pelo governo, o liberalismo de Guizot parte de uma relação fundamentalmente cínica com a liberdade, produzindo uma teoria que, em verdade, buscaria dar novos instrumentos de legitimidade a um Estado que se imporia sobre o indivíduo, tal como na interpretação de Jaume, mascarando a razão de Estado em uma nova ordem política organizada pelo princípio dos direitos individuais, das liberdades públicas e do sistema representativo.

Contudo, como procuramos desenvolver ao longo do presente artigo, buscamos uma interpretação distinta: o 
desafio colocado pelo pensamento de Guizot é o de como pensar essa nova e inevitável dimensão do político pós-revolucionária, não contra o poder - como o liberalismo do sujeito o faz - mas a partir dele, ou seja, a partir da constituição de uma nova autoridade legítima. A sociedade é o espaço por excelência de permanência da herança revolucionária: lidar com ela e convertê-la em um efetivo meio de governo, em "mercado político", é o verdadeiro objetivo do liberalismo doutrinário de Guizot. Imbuído da convicção de que sua tarefa era dirigir a "França Nova", seu desafio teórico e político era como pensar as transações possíveis entre o Estado e a nova sociedade - e ele sabia que esse desafio teórico e político não poderia ser resolvido apartado do plano da História.

\section{Paulo Henrique Paschoeto Cassimiro}

Bacharel em Ciências Sociais (UFF), mestre e doutor em Ciência Política (IESP-UERJ). Desenvolve pós-doutorado no Departamento de Ciência Política da Universidade de São Paulo, com apoio da Fapesp. Atua nas áreas de teoria política moderna, pensamento político brasileiro e teoria da democracia.

\section{Felipe Freller}

Bacharel em Ciências Sociais (USP), mestre em Ciência Política (USP), doutor em Ciência Política pela USP e pela École des Hautes Études en Sciences Sociales (EHESS) e pesquisador associado do Centre d'Études Sociologiques et Politiques Raymond Aron (CESPRA). Atua na área de teoria política moderna.

\section{Bibliografia}

ARON, Raymond. 1987. Démocratie et totalitarisme. Paris: Folio Essays. ARMENTEROS, Carolina. 2011. The french idea of history: Joseph de Maistre and his heirs, 1794-1854. Ithaca: Cornell University Press. 
BONALD, Louis de. 1859. CEuvres complètes de M. de Bonald. Paris: J. P. Migne. 3 v.

BONALD, Louis de. 1988. Réflexions sur la Révolution de Juillet 1830 et autres textes inédits. présentation et analyse de Jean Bastier. Paris: DUC-Albatros.

CARVALHO, José Murilo de (org.). 2002. Visconde do Uruguai. São Paulo: Editora 34.

CASSIMIRO, Paulo. 2018. O império da opinião: espaço público, opinião pública e a legitimidade do político no argumento liberal francês. Dados, v. 61, n. 3, pp. 659-693.

CASSINA, Cristina. 2007. Parole vecchie, parole nuove: ottocento francese e modernità politica. Roma: Carocci.

CONSTANT, Benjamin. 1964. Écrits et discours politiques. Paris: Jean-Jacques Pauvert. v. 1.

CRAIUTU, Aurelian. 2003. Liberalism under siege: the political thought of the french doctrinaires. Lanham: Lexington Books.

FRELLER, Felipe. 2015. Guizot, Tocqueville e os princípios de 1789. Dissertação de Mestrado em Ciência Política. São Paulo: Universidade de São Paulo. Disponível em: https://bit.ly/3pg1jLY. Acesso em: 10 nov. 2020.

FRELLER, Felipe. 2016. Guizot, Tocqueville e os princípios de 1789. Revista Estudos Políticos, v. 7, n. 2, pp. 179-201.

FURET, François. 1982. L'Atelier de l'histoire. Paris: Flammarion.

GUIZOT, François. 1844. Essais sur l'histoire de France: pour servir de complément aux observations sur l'histoire de France de l'abbé de Mably. 6. ed. Paris: Charpentier.

GUIZOT, François. 1845. Histoire de la Révolution d'Angleterre: depuis l'avènement de Charles I jusqu'à sa mort. T. I. 4. ed. Paris: Didier.

GUIZOT, François. 1849. De la démocratie en France. Paris:

Victor Masson, Librairie.

GUIZOT, François. 1886. Histoire des origines du gouvernement représentatif et des institutions politiques de l'Europe (II Tomes). Paris: Didier et co.

GUIZOT, François. 1985. Histoire de la civilisation en Europe: depuis la chute de l'empire romain jusqu'à la révolution française : [suivie de] philosophie politique de la souveraineté. Paris: Hachette.

GUIZOT, François. 1987. Des moyens de gouvernement et d'opposition dans l'état actuel de la France. Paris: Belin.

JAUME, Lucien. 1992. Guizot et la philosophie de la représentation. Droits, n. 15, pp. 141-152.

JAUME, Lucien. 1997. L'individu effacé, ou le paradoxe du libéralisme français. Paris: Fayard.

JAUME, Lucien. 2008. Tocqueville: les sources aristocratiques de la liberté. Paris: Fayard. 
LEFORT, Claude. 1994. L'invention démocratique: les limites de la domination totalitaire. Paris: Fayard.

MANIN, Bernard. 1997. The principles of representative government.

Cambridge: Cambridge University Press.

MARX, Karl; ENGELS, Friedrich. 1983. Collected works. Londres: International Publishers. v. 39.

MELLON, Stanley. 1958. The political uses of history: a study of historians in the french restoration. Stanford: Stanford University Press.

NEMO, Philippe; PETITOT, Jean. 2006. Histoire du libéralisme en Europe. Paris: PUF.

ROSANVALLON, Pierre. 1985. Le moment Guizot. Paris: Gallimard.

ROSANVALLON, Pierre. 2000. La démocratie inachevée: histoire de la souveraineté du peuple en France. Paris: Gallimard.

ROSANVALLON, Pierre. 2004. Le modèle politique français: la société civile contre le jacobinisme de 1789 à nos jours. Paris: Éditions du Seuil.

SCHMITT, Carl. 2006. Teologia política. São Paulo: Del Rey.

SPAEMANN, Robert. 2002. L'origine della sociologia dallo spirito della restaurazione. Bari: Laterza.

TOCQUEVILLE, Alexis de. 1989. CEuvres complètes: mélanges. Paris: Gallimard. v. 16.

TOCQUEVILLE, Alexis de. 2009. O antigo regime e a revolução. São Paulo: WMF Martins Fontes. 


\section{ESTADO E SOCIEDADE CIVIL NA TEORIA POLÍTICA FRANCESA DO SÉCULO XIX: $O$ DEBATE SOBRE A FORMAÇÃO DA SOCIEDADE PÓS-REVOLUCIONÁRIA}

PAULO HENRIQUE PASCHOETO CASSIMIRO

\section{FELIPE FRELLER}

Resumo: Este artigo revisita o debate teórico do século XIX sobre os papeis do Estado e da sociedade civil na formação da sociedade pós-revolucionária, a partir do qual buscamos discutir certas interpretações que enfatizaram como a constituição da sociedade moderna pressupõe a articulação entre a esfera do Estado - como polo de institucionalização do poder legítimo - e da sociedade civil - como espaço de um novo sujeito da legitimidade política. A ênfase recai sobre François Guizot e seus esforços para conciliar a existência de um Estado centralizador e a emergência de uma sociedade civil protagonista da legitimidade política moderna. Ao mesmo tempo, buscamos contrastá-lo com as interpretações de Louis de Bonald, que critica a possibilidade de uma legitimidade política calcada na esfera da sociedade civil; e a de Alexis de Tocqueville, para quem o Estado monárquico centralizado teria impedido a formação e a expressão política plena da sociedade civil francesa.

Palavras-chave: Estado; Sociedade Civil; França; Liberalismo; Conservadorismo; Democracia.

\section{STATE AND CIVIL SOCIETY IN THE 19TH CENTURY FRENCH POLITICAL THEORY: DEBATE ON THE FORMATION OF POST- REVOLUTIONARY SOCIETY}

Abstract: This paper revisits the theoretical debate of the 19th century on the roles of the State and civil society in the formation of post-revolutionary society, from which we will discuss certain interpretations that emphasized how the constitution of modern 
society presupposes the articulation between the sphere of the State - as a pole of institutionalization of legitimate power - and of civil society - as a space of a new subject of political legitimacy. We focus on François Guizot and his theoretical efforts to reconcile the existence of a centralized state and the emergence of a civil society that is the protagonist of modern political legitimacy. At the same time, we contrast it with the interpretations of Louis de Bonald, who criticizes the possibility of political legitimacy based on the sphere of civil society; and Alexis de Tocqueville, who believed that the centralized monarchical state would have prevented the formation and full political expression of French civil society.

Keywords: State; Civil Society; France; Liberalism; Conservatism; Democracy.

Recebido: 15/11/2017 Aprovado: 28/10/2020 